\title{
BOALA STILL A ADULTULUI ŞI POLIATRITA REUMATOIDĂ. OBSERVAȚIE CLINICĂ ASUPŔA UNUI CAZ
}

\section{Virag Tiberiu'}

${ }^{1} C M I$, medic specialist medicina familiei

\section{Title: Still Desease at adult and Rheumatoid Poliartritis. Clinical case.}

Abstract: I present a more rare case of Still Desease at a 49 years old female, which put uncertainty on differential diagnosis, with insidious debut and minor changes at the small joints.

Key words: Still Desease, Rheumatoid Poliartritis, swing fever, rash, anaemia.

Rezumat: Prezint un caz mai rar de boală Still la o persoană de sex feminin de 49 ani, care a pus probleme de diagnostic diferențial, debutând insidios, cu modificări minore la nivelul articulațiilor mici.

Cuvinte cheie: boala Still, poliartrită reumatoidă, pusee febrile, erupție tegumentară, anemie.

\section{Introducere}

Boala Still este o afecțiune asemănătoare poliartritei reumatoide, cu debut înainte de vârsta de 17 ani, care afectează în primul rând sexul feminin [5]. Sinovita care persistă cel puțin șase săptămâni este criteriul esențial de diagnostic [5]. Boala poate apare mai rar și la adult ca în cazul nostru, dar pune probleme de diagnostic diferențial cu leucemia sau limfomul, boala intestinală inflamatorie sau afecțiuni infecțioase cronice (boala Lyme).

Istoricul bolii: debut insidios în ianuarie $2009 \mathrm{cu}$ modificări minore la nivelul articulaţiilor mici, apoi febră înaltă $38,7^{\circ} \mathrm{C}$, erupții tegumentare morbiliforme maculopapulare în jumătatea superioară a toracelui, fața anterioară a coapselor, limfadenopatie laterocervicală și angină eritematoasă. S-a interpretat cazul ca un lupus eritematos, vasculită alergică, dar care nu a răspuns la tratamentul cu AINS, antibiotice și corticoterapie, având o evoluție ondulantă.

Examinările paraclinice: IgG 593 (VN 700-1600), VSH 66mm/h (VN 1-20), fibrinogen $674,5 \mathrm{mg} / \mathrm{dl}$ (VN 200-400), anticorpi antinucleari negativi, anticorpi antiproteinază 3 negativ, complement C4 $57 \mathrm{mg} / \mathrm{dl}$ (VN 10-40), proteina C reactivă CRP $12 \mathrm{mg} / \mathrm{l}(\mathrm{VN}<6)$.

În urma examinărilor paraclinice se suspectează o poliartrită reumatoidă, motiv pentru care pacienta se internează la Clinica de Reumatologie Cluj Napoca, unde se pune diagnosticul de boala Still a adultului, în observație. Pe perioada internării, pe baza examinărilor clinice, paraclinice, radiologice, ecografice, biologice (sindrom inflamator, feritina crescută), splenomegalie, s-a instituit tratament cu prednisonum $20 \mathrm{mg} / \mathrm{zi}$ în asociere cu hidroxiclochină, $2 \times 200 \mathrm{mg} / \mathrm{zi}$, tratament antibiotic cu amoxicilină cu acid clavulanic $2 x 1 \mathrm{~g} / \mathrm{zi}$, paracetamol cu pseudoefedrină 3x1 cp/zi, vitamina C $1 \mathrm{~g} /$ zi. 
În februarie 2009, pacienta revine la control la Clinica din Cluj Napoca și pe baza examinărilor clinice și paraclinice efectuate se stabilește diagnosticul de boala Still a adultului și poliatrită reumatoidă, se instituie tratament de lungă durată cu hidroxiclorochină $2 \times 200$ mg/zi, colchicină 1 $\mathrm{mg} / \mathrm{zi}$, prednison $3 \times 5 \mathrm{mg} / \mathrm{zi}$.

După două luni probele biologice arată: exudat faringian negativ, CRP 6 mg/l, GOT 65,3 U/1

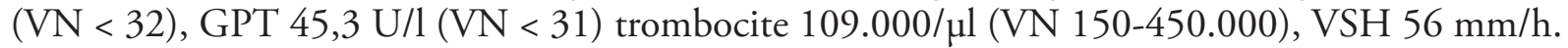

În iunie 2009, la controlul ambulator, pacienta prezintă: VSH 96 mm/h, CRP 9 mg/l, AST 35,4 U/l, Hb 10,5 g/dl și se introduce în tratament metotrexat $5 \mathrm{mg} / \mathrm{săptămână,} \mathrm{prednison} 15 \mathrm{mg} / \mathrm{zi}$, hidroxiclorichină $2 \times 200 \mathrm{mg} / \mathrm{zi}$, urmând o creștere a metotrexatului la $10 \mathrm{mg} /$ săptămână în saptămâna a doua, apoi la $15 \mathrm{mg} /$ săptămână, în săptămâna a treia, acid folic $3 \times 1 \mathrm{cp} / z i, 3$ zile/săptămână în zilele fără metotrexat, pentoxifilină $2 \times 400 \mathrm{mg} / \mathrm{zi}$.

Deoarece la controlul în ambulator a prezentat o erupție "salmon pink" pe fața externă a braţului drept și erupție papulară cu baza eritematoasă intens pruriginoasă la nevelul toracelui anterior, submamar, interpretată de dermatolog ca o eczemă cronică lichenificată, s-a interpretat ca un fenomen Raynaud; pentru eczema cronică se instituie tratament cu fluconazol, mometasonă și metilprednisolon local.

În iulie 2009 pacienta se prezintă la cabinetul meu pentru o erupție eritematoasă de aspect eczematizat pe toracele anterior, antebraț, ambele gambe (foto 1,2 ) și la nivelul scalpului, pruriginoase.

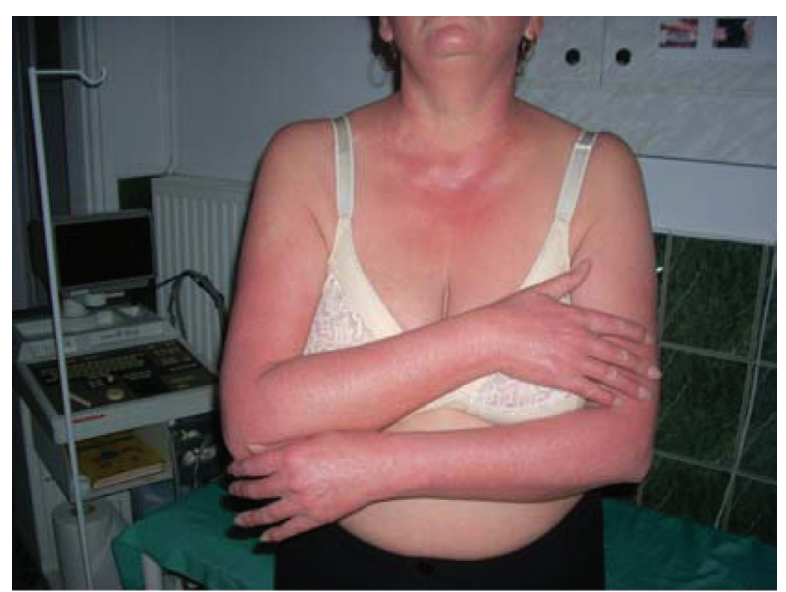

Foto 1

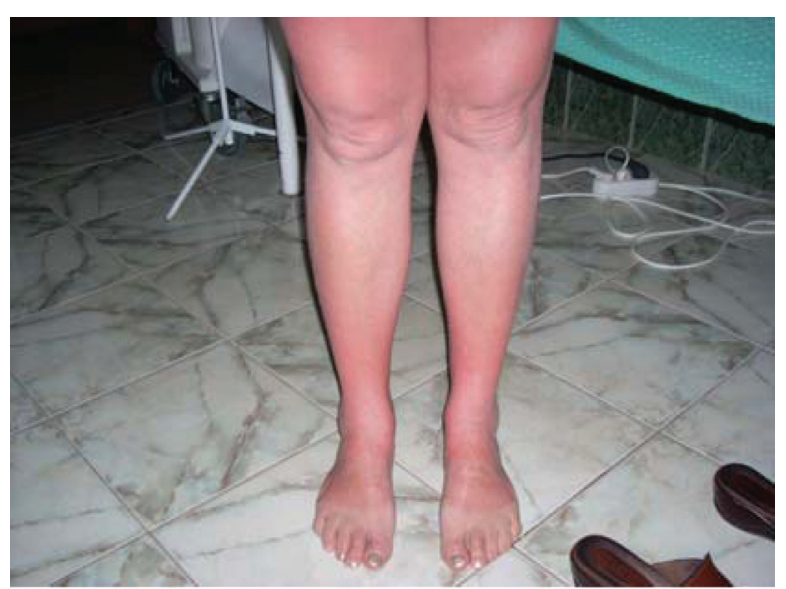

Foto 2

Examinările paraclinice arată o hipoalbuminemie 48,8 \% (VN 52-68), gammaglobulinele 25,5 \% (VN 11-21), IgG 825 (VN 700-1600), IgE 94,4 (VN<100), VSH 38 mm/h.

Pe baza examenului clinic, paraclinic și antecedentelor am interpretat erupția eczematiformă ca fiind secundară tratamentului medicamentos, motiv pentru care s-a sistat tratamentul anterior și am trecut la detoxifiere prin administratrea de antialergice, diuretice și perfuzii cu hepatoprotectoare, evoluția fiind favorabilă, pruritul dispărând, eczema retrăgându-se în proporție de 90 \% (foto 3,4).

Starea generală s-a ameliorat, tratamentul extern al tegumentelor a fost realizat prin aplicarea de uleiuri naturale (cătina, in), iar ca și tratament antiinflamator am folosit betametazonă o fiolă pe săptămână, combinată cu etoricoxib $120 \mathrm{mg} / \mathrm{zi}$, urmând ca în luna septembrie să se prezinte la clinica de reumatologie Cluj Napoca pentru o nouă evaluare.

\section{Concluzii}

În cazul sindroamelor febrile prelungite fără etiologie precizată, după excluderea unui proces infecțios cronic sau al unei boli canceroase, ne putem gândi și la boala Still, ca și precursoare a poliartritei reumatoide. 


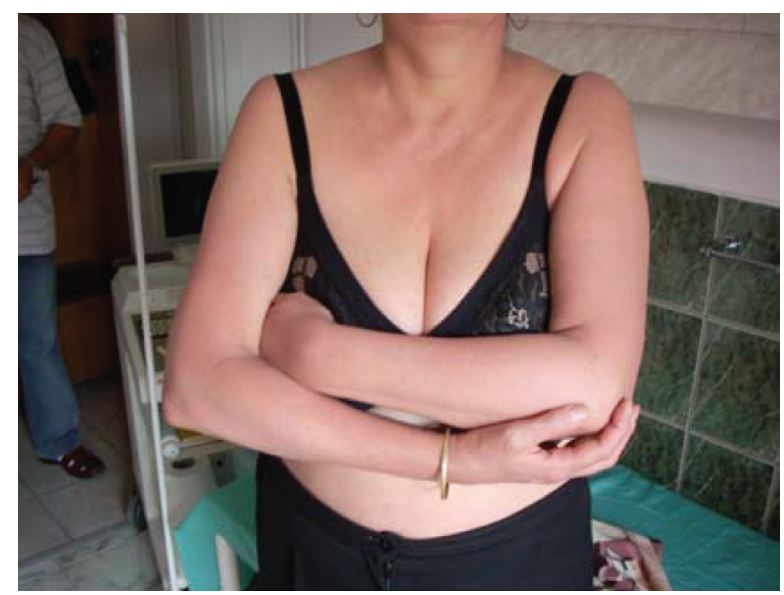

Foto 3

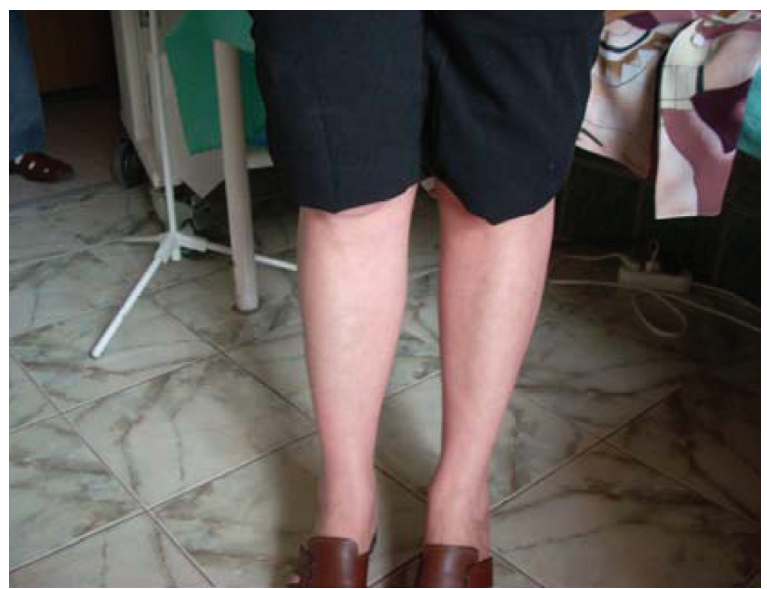

Foto 4

În cazul prezentat am observat o evoluție ciclică a bolii Still și a poliartritei reumatoide, cu perioade de remisie și exacerbări, cu intoleranță la imunosupresoare de tip metotrexat.

Se impune reeducarea funcțională prin tehnici de kinetoterapie și ergoterapie, asociată cu agenți fizici, masaj, balneoterapie [1].

Rolul medicului de familie este suspicionarea afecțiunii, cu îndrumarea spre investigațiile necesare, supravegherea evoluției, prevenirea complicațiilor, evaluarea rezultatelor terapeutice, depistarea reacțiilor adverse, adaptarea tratamentului la particularitățile pacientului, precum și colaborarea cu specialiștii de profil.

\section{Referințe}

1. Restian, A. Bazele medicinei de familie. Ed. Medicală, Bucureşti, 2003,481-488

2. American College of Rheumatology and ad hoc committee. Clinical Guidelines for the management of Rheumatoid Arthritis, Rheum, 1966,39:713-722

3. American College of Rheumatology. Position statement. Metotrexate, Council on Rheumatologic, CAR, 1991:5-20

4. Colegiul Medicilor din România. Ghiduri de practică medicală, vol I, Ed. Info Medica, 2002,237

5. McTierney, L, McPhee, S.I, Maxine, A, Papadakis, A. Diagnostic şi tratament în practica medicală, Ed. internațională, McGraw Hill, 2001,676-682 